Theories \& Applications, the International Edition

Printed Version: (ISSN 2090-5262)

Online Version: (ISSN 2090-5270)

November 2013, Volume 3, No. 3 Pages (67 - 77)

\title{
The Effect of a Sports Program on the Motor Abilities of Preschool Children
}

\author{
Nasser Omar Alwasif*
}

\begin{abstract}
The Purpose of this research was to determine the effect of a sport program on the motor abilities of 79 Egyptian preschool children (41 children in the experimental group and 38 children in the control group), all at the aged of five. The sport program assigned to the preschool children was applied over the experimental group for 12 weeks, holding every week 3 sessions for 50 minutes. Differences in motor abilities between the experimental and control group were observed pre and post 3months of intervention. The following motor ability tests were used: sit-and-reach, standing long jump, shuttle-run $4 \times 10 \mathrm{~m}$, sand bag $(150 \mathrm{~g})$ throw with the dominant hand, sit-ups for $30 \mathrm{sec}$, and shuttle-run $3 \mathrm{~min}$. The results showed that there was no difference between the groups in pre intervention, while in the final check there was a statistically significant difference showing the advantage of the experimental group, which points out that the children who participated in the sport program improved their motor abilities.
\end{abstract}

Keywords: motor abilities, motor development; preschool children;

\section{Introduction}

$\mathrm{T}$ he preschool years are known as the "Golden Age" of motor development. It is during these years (3-to 5-years of age) that important skills like running, jumping, throwing and catching are developed. Through play and physical activity, kids learn and practice skills that become building blocks of more complicated movements. (Shenouda, Gabel, \& Timmons, 2011)

Studies in the field of child development not only inform about the development condition and direction but also represent scientific information's about how and what will be taught. Movement is one of the most important factors that contribute to child development. Children love moving. Movement is a part of the child's life from the beginning of the birth. So there are so many reasons to support the children's movement opportunities. It is declared that real learning and growth occurs at the time of movement (Hu1-Tzu 2003).

\footnotetext{
* Department of Sport Kinesiology, Faculty of Physical Education, Al-Minia University, Egypt
}

One of the forms in which movement education training performed is Sport. Sport is a tool that provides the physical, mental, emotional and social development and improves intelligence, skill and leadership skills of the child. Major objective of the child's sport should be to raise cardiovascular endurance and to develop neuromuscular coordination, power and flexibility. These features can be entitled to the preschool and primary education children in the form of game by pedagogical approchement (Demiral 2011).

The level of motor ability in children and adolescents has been discussed intensively during the past few years. The development of motor competence during infancy and childhood is dependent upon and influenced by various factors such as age, gender, and physical activity (Butterfield et al. 2002; Finn et al. 2002; Dowda et al. 2004; Graf et al. 2004; Dorfberger et al. 2009; Venetsanou \& Kambas, 2010; Shenouda et al. 2011).

Until the age of seven, children learn the basic types of motor activity, which stimulates the process of development of their basic motor abilities, among them coordination, speed, 
strength, flexibility, balance, and precision, and it is difficult to make up for the lack of these abilities later on. Therefore, one should bear in mind that preschool children are at the best age for the stimulation of motor abilities and thereby of intellectual potential, both of which will be built up during their entire lifetime (Graham, Holt/Hale \& Parker, 1998).

The influence of motor development is of critical importance to the development of preschool children in general. Children grow and develop intensively and therefore the necessity for their motor activity increases. Therefore, a lack of playing, experience and the opportunity to take part in different physical activities can slow down their regular process of development (Finn, Johannson \& Specker 2002; Brown et al., 2006).

In general, nervous system growth is significant in preschool-aged childhood; therefore, in physical strength, motor coordination is said to be significant compared with muscle strength and power (Malina \& Bouchard, 1991). In preschool-aged children, the interest and ability in movement for both males and females are highly analogous; therefore, male children and female children can be grouped together for physical education at this stage (Gallahue \& Donnelly, 2003).

In recent years there has been more and more scientific research and thereby more and more theories have appeared regarding the necessity for the physical exercise of preschool children (Sanders, 1993., Kostiü, et al., 2003., Jackson et al., 2003., Pate et al., 2004., Melody, et al., 2007).

Research has demonstrated that if children feel confident about their motor ability they engage more often in physical activities compared with those children who lack confidence in this area (Mandich, Polatajko, \& Rodger, 2003; Hay, Hawes, \& Fraught, 2004). This suggests that targeting motor skills development may be a suitable approach to increasing physical activity participation in children, known to be important for the prevention of obesity and cardiovascular disease (Biddle, Gorely, \& Stensel, 2004).

If children are not able to allow proper motor development and make progress in their motor abilities and skills, it is more likely that they will have less self-confidence, and more difficulties when communicating with their environment, as well as in handling everyday situations. In most cases, these children will not do the minimum physical activities necessary for a healthy and productive life once they are grown-ups (Strauss et al., 2001).

For this reason, the number of sports programs ensuring the appropriate growth, development and health of preschool children is increasing (Council on Physical Education for Children 1992, Sanders, 1992, Avery, 1994, Werner, 1997, Graham et al. 1998, National Association for Sport and Physical Education, 2002).

Well organized programs for physical activities are useful in several respects; through the development of motor activities, children's cognitive, social and emotional skills will be developed. The quality of these sports programs will greatly depend on the feedback concerning the development of motor abilities, as well as on the healthy growth and development of the children (Dowda, 2004).

Because of the basic necessity for the healthy growth and development of children, and in order to allow a positive influence on their motor abilities, a special sports program for preschool children was developed. The realization of the sports program made it possible to observe every individual child and to learn more about the effects of this kind of program. Therefore, the purpose of this paper was to determine the improve in some of the motor abilities of Egyptian preschool children (age five) that took place as a consequence of a three-month experimental sports program.

\section{Method}

\section{Participants}

The subjects were 79 normal healthy Egyptian preschool children from Elminia, Egypt. The physical characteristics of the subjects are presented in Table 1. Age was expressed in months, height in $\mathrm{cm}( \pm 0.1 \mathrm{~cm})$, and body weight in $\mathrm{kg}( \pm 0.05 \mathrm{~kg})$. 
Table (1)

The physical characteristics of the subjects

\begin{tabular}{|c|c|c|c|c|c|c|c|}
\hline \multirow[t]{2}{*}{ Variables } & \multirow{2}{*}{$\begin{array}{c}\text { the total } \\
\mathrm{n}=79 \\
\text { mean }\end{array}$} & \multicolumn{2}{|c|}{$\begin{array}{c}\text { Cont. group } \\
\mathrm{n}=38\end{array}$} & \multicolumn{2}{|c|}{$\begin{array}{l}\text { Exp. Groups } \\
\quad \mathrm{n}=41\end{array}$} & \multirow[t]{2}{*}{$\mathrm{t}$} & \multirow{2}{*}{$\mathrm{p}$} \\
\hline & & M1 & SD1 & M2 & $\mathrm{SD} 2$ & & \\
\hline Age (month) & 62.86 & 62.55 & 2.01 & 63.15 & 2.03 & 1.31 & .196 \\
\hline Height (cm) & 108.52 & 108.79 & 3.22 & 108.27 & 3.87 & 0.65 & .519 \\
\hline Weight $(\mathrm{kg})$ & 20.41 & 20.53 & 2.25 & 20.29 & 2.41 & 0.44 & .658 \\
\hline
\end{tabular}

The experimental group consisted of 41 children at the age of five. They all took part in the three month sports program for preschool children, which were carried out three times per week for 50 minute sessions. The sports program's sessions were conducted by a teacher of physical education. The control group consisted of 38 children at the age of five, who had a regular kindergarten program.

\section{Measures}

The motor tests were selected for ease of administration. All are valid and reliable in children older than 4 years (Safrit, 1990), initial and final measuring were carried out with the aim out of determining their motor abilities.

All of the measurements were administered by one trained researcher using standardized equipment. The children wore sport clothing and footwear during the testing. The time interval between the tests was $10-15 \mathrm{~min}$. The following tests were used after a short (5-7 min) warm up in the following order:

The estimation of the motor efficiency of the five-year-olds (the experimental and control group) was carried out by a battery of 6 tests (Trajkovski - Višiü, 2004),

Sit-and-reach (S\&R) (flexibility) was measured in the sitting position to the nearest $\mathrm{cm}$. The plate extended $15 \mathrm{~cm}$ over the side supporting the feet. The best of three attempts was recorded.

Standing long jump (SLJ) (explosive strength) was measured to the nearest $\mathrm{cm}$. The subject stood with their toes just behind the takeoff line. After a maximal effort, the subject landed on the mat feet together and remained upright. The best of three attempts was recorded.

Shuttle-run $4 \times 10 \mathrm{~m}$ (SR4x10) (running speed, agility) consisted of a running and turning test at maximum speed between two parallel lines drawn on the floor. Two children were allowed to run simultaneously. The result was measured with a stopwatch to the nearest of $0.1 \mathrm{sec}$.

Sand bag $(150 \mathrm{~g})$ throw for distance with dominant hand (SB) (explosive strength, coordination) was done in the standing position with an over arm motion. Each throw was measured to the nearest $0.1 \mathrm{~m}$. Three attempts and the best was recorded. The test was demonstrated by the researcher.

Sit-ups for $30 \mathrm{sec}$ (SU) (trunk strength) were done in the subject sitting on a mat, back upright, hands clasped behind the neck, knees bent at $90^{\circ}$, and the feet flat on the mat. The number of repetitions in $30 \mathrm{~s}$ was measured.

Shuttle-run, $3 \mathrm{~min}$ (SR3M) (cardio respiratory endurance) was based on the test of Kaneko and Fuchimoto (1993). Two poles (1.5 m height) were placed $10 \mathrm{~m}$ apart so as to prepare a straight $10 \mathrm{~m}$ running track along which four points were marked by tape. The subject ran from one side to the other, went around the pole, and then returned to the starting point. The distance covered in $3 \mathrm{~min}$ was measured $( \pm 5 \mathrm{~m})$.

\section{Sports program}

In Order to design this sports program, the researcher access to many of the previous studies and research Council on Physical Education for Children (COPEC). (1992), Sanders, (1992) , Community Information Service, (1996), South Eastern Sydney Illawarra Area Health Service (1997), Finn, et al. (2002), Mitchell, et al. (2002), National Association for Sport and Physical Education. (2002), Brian, et al. (2007).

Well organized programs for physical activities are useful in several respects; through the development of motor activities, children's cognitive, social and emotional skills will be developed. The quality of these kinesiology programs will greatly depend on the feedback concerning the development of motor abilities, 
as well as on the healthy growth and development of the children (Dowda, 2004).

Because of the basic necessity for the healthy growth and development of children, and in order to allow a positive influence on their psychomotor abilities, a special sports program for preschool children was developed (Hraski and Živiü, 1996).

The sports program focused on the need for promotion of gross motor skills. A structured exercise program focusing on balance, jumping or ball skills. The Program use of games to promote gross motor skills and it identifying and helping children with poor gross motor skills Sanders, (1993), Technical Assistance \& Training System (TATS) (2010), Shenouda, et al. (2011).

\section{Experimental Procedure}

The experiment was conducted in kindergartens in Elminia, Egypt. Both the experimental and control group were tested by means of the aforementioned motor tests at the beginning and at the end of the experimental program.

The first measurements were made in October, the last were made in January, with the same battery of motor tests over the same period of time.

The sports program was administered over experimental group for 12 weeks and every week 3 sessions (36 sessions) for 50 minutes. During that period, the children had 32 hours of planned and organized sports training. By learning and performing basic kinesiological movements and the fundamental techniques in different sports and by playing different elementary games, the children were under continual influence to develop their basic motor abilities. During this period the control group did nothing just a regular kindergarten program.

\section{Statistical analyses}

An SPSS statistical package (Version 17) was used to analyze the data. The collected data was processed as follows:

1. Basic statistical data (descriptive statistics) were calculated for every item.

2. The statistically significant difference between the initial and final measuring of the experimental group and control group was calculated by means of the T-test for dependent samples.

3. The results of the initial and final measuring of the experimental and control group were compared using a T-test for independent samples (Student's T-test).

4. The comparison of the progress of the experimental and control group in each test was calculated on an individual level for each sample and for each test by subtracting the result of the initial measuring from the result of the final measuring (Student's T-test).

5. The discriminant analysis (backward stepwise) illustrated which tests showed the most significant difference between the experimental and control group.

6. The level of significance was set at $\mathrm{p} \# 0.05$.

Due to the different measurement approaches in individual items for forming scales had the item scores are Z-transformed. Thereby serve as normative values, the average value and the standard deviation of the final measuring of the experimental group.

\section{Results and Discussion}

The statistically significant difference in the results from the first and second measuring of the experimental and control group was calculated using a T-test for dependent samples. On the basis of the results, the effects of the program were monitored. What was also monitored was whether there was any statistically significant progress between the first and second measuring of the experimental and control group.

The results shown in Table 2 and 3 refer to: the arithmetic mean from the initial and final measuring (M1 and M2), standard deviation (SD1 and SD2) from the initial and final measuring, the mean difference (Mean Diff.), the T-test for dependent samples (t), and statistical significance (p).

The comparison of the initial and final measuring (Table 2) (Figure 1-A) (Figure 1-B) makes it obvious that the control group made a statistically significant improvement in their results in more than $90 \%$ from the motor tests at 
the final measuring, although the children did not take part in systematic exercise, so this can be seen as part of the regular process in the growth and development of children.

By comparing the results from the initial and final measuring, a conclusion can be made that the control group achieved a statistically more significant difference in improving their results from the final measuring, compared to the initial measuring for the following variables: sit-andreach (S\&R), standing long jump (SLJ), shuttlerun $4 \times 10 \mathrm{~m}(\mathrm{SR} 4 \times 10)$, sand bag (SB), and shuttle-run in $3 \mathrm{~min}(\mathrm{SR} 3 \mathrm{M})$. There was no statistically significant difference found for the variable: sit-ups for $30 \mathrm{sec}$ (SU).

Table (2)

Results of the initial and final measuring of the control group $(n=38)$

\begin{tabular}{|c|c|c|c|c|c|c|c|}
\hline \multirow{3}{*}{ Variables } & \multicolumn{4}{|c|}{ Measuring } & \multirow{3}{*}{$\begin{array}{c}\text { Mean } \\
\text { Diff. }\end{array}$} & \multirow{3}{*}{$\mathrm{t}$} & \multirow{3}{*}{$\mathrm{p}$} \\
\hline & \multicolumn{2}{|c|}{ Initial } & \multicolumn{2}{|c|}{ Final } & & & \\
\hline & M1 & SD1 & M2 & SD2 & & & \\
\hline $\mathrm{S} \& \mathrm{R}(\mathrm{cm})$ & 20.08 & 3.03 & 21.13 & 3.01 & 1.05 & 7.76 & $.000 * *$ \\
\hline $\mathrm{SLJ}(\mathrm{cm})$ & 90.16 & 2.87 & 90.53 & 2.56 & 0.37 & 2.22 & $.033 *$ \\
\hline SR4x10 (s) & 15.20 & 1.84 & 14.66 & 1.25 & 0.54 & 2.25 & $.030 *$ \\
\hline $\mathrm{SB}(\mathrm{cm})$ & 484.11 & 5.69 & 485.39 & 6.48 & 1.29 & 3.44 & $.001 * *$ \\
\hline SU (n/30s) & 7.39 & 1.82 & 7.71 & 1.58 & 0.32 & 2.02 & .050 \\
\hline SR3M (m) & 297.20 & 2.90 & 301.63 & 2.62 & 3.43 & 6.98 & $.000 * *$ \\
\hline
\end{tabular}

The results of the sit and reach test improved on measuring to $90.53 \mathrm{~cm}$ in the final one and average by $1.05 \mathrm{~cm}$ in the final measuring, which is a significant improvement. The children improved their result in the standing long jump test from $90.16 \mathrm{~cm}$ in the initial a statistically significant progress.

Figure (1-A)

Results of the initial and final measuring (Z-Score) of the control group $(n=38)$

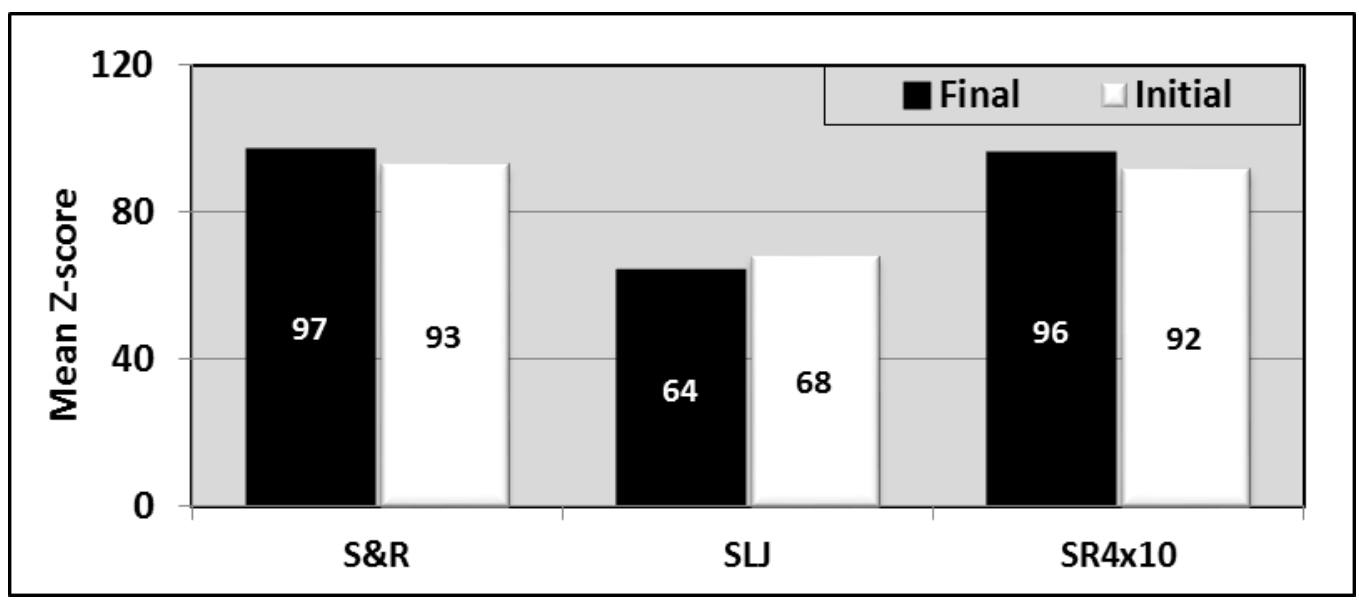

There was a statistically significant improvement in the results of the sand bag throw test, the children improved their result from $484.1 \mathrm{~cm}$ in the initial measuring to 485.4 $\mathrm{cm}$ in the final one. In the test "shuttle run 3 min", the children improved their result by 3.43 meter and made a statistically significant progress. But there was no a statistically significant improvement in the results of the situps test.

The reason why they did not show improvement in the sit-ups test is mainly because repetitive strength is influenced by regular exercise and by doing specific exercises. 
Figure (1-B)

Results of the initial and final measuring (Z-Score) of the control group $(n=38)$

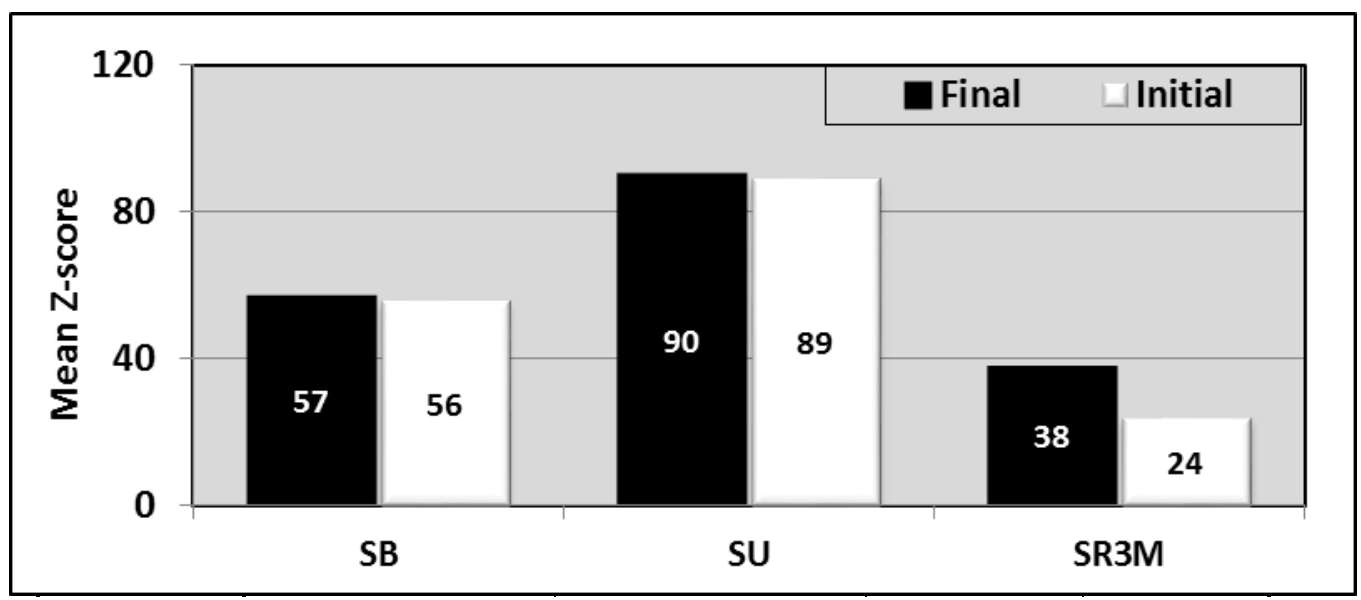

The comparison of the initial and final made a statistically significant improvement in measuring (Table 3) (Figure 2-A) (Figure 2-B) their results in all of the motor tests at the end of makes it obvious that the experimental group the three-month sport program.

Table (3)

Results of the initial and final measuring of the experimental group $(n=41)$

\begin{tabular}{|c|c|c|c|c|c|c|c|c|c|}
\hline \multirow{2}{*}{ Variables } & \multicolumn{5}{|c|}{ Initial } & \multicolumn{2}{c|}{$\begin{array}{c}\text { Mean } \\
\text { Diff. }\end{array}$} & $\mathrm{t}$ & $\mathrm{p}$ \\
\cline { 2 - 10 } & M1 & SD1 & & M2 & SD2 & & & \\
\hline S\&R (cm) & 20.17 & 3.31 & & 22.24 & 3.27 & 2.07 & 15.13 & .000 \\
\hline SLJ (cm) & 90.20 & 3.28 & & 101.07 & 3.43 & 10.88 & 43.97 & .000 \\
\hline SR4x10 (s) & 15.40 & 1.86 & 14.21 & 1.21 & 1.20 & 5.98 & .000 \\
\hline SB (cm) & 484.60 & 6.24 & 526.27 & 9.52 & 41.68 & 25.29 & .000 \\
\hline SU (n/30s) & 7.66 & 1.87 & 9.44 & 1.80 & 1.78 & 5.68 & .000 \\
\hline SR3M (m) & 298.35 & 3.12 & & 321.51 & 3.18 & 24.61 & 32.16 & .000 \\
\hline
\end{tabular}

The sit and reach is an exercise dominated by be strongly influenced, especially in the case of the flexibility of the back side of the legs. It was children of a very young age. The children already mentioned that flexibility is a motor improved their result In this test by $2 \mathrm{~cm}$ and ability which is determined by heredity and can made a statistically significant improvement.

Figure (2-A)

Results of the initial and final measuring (Z-Score) of the experimental group $(n=41)$

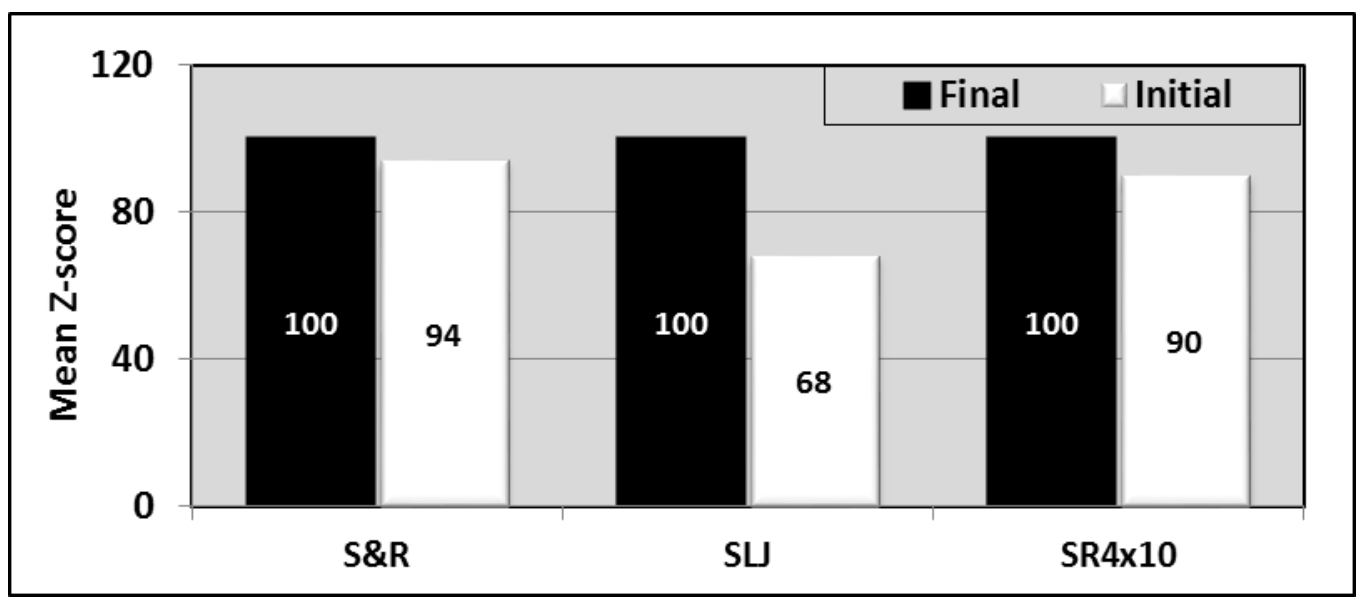

The results of the standing long jump test improved on average by $11 \mathrm{~cm}$ in the final measuring, which is a significant improvement.
The children repeated this test and their results improved each time. The conclusion is that 
learning is an important factor in this exercise and the children learned by repeating it.

In the test "shuttle run $4 \times 10$ ", the children improved their result by 1.2 seconds and made a statistically significant progress over the threemonth period. Since the program involved a great number of activities including coordination - agility, a conclusion can be made that it enabled faster and better skill development of running fast with a change in direction.

Figure (2-B)

Results of the initial and final measuring $(Z-S c o r e)$ of the experimental group $(n=41)$

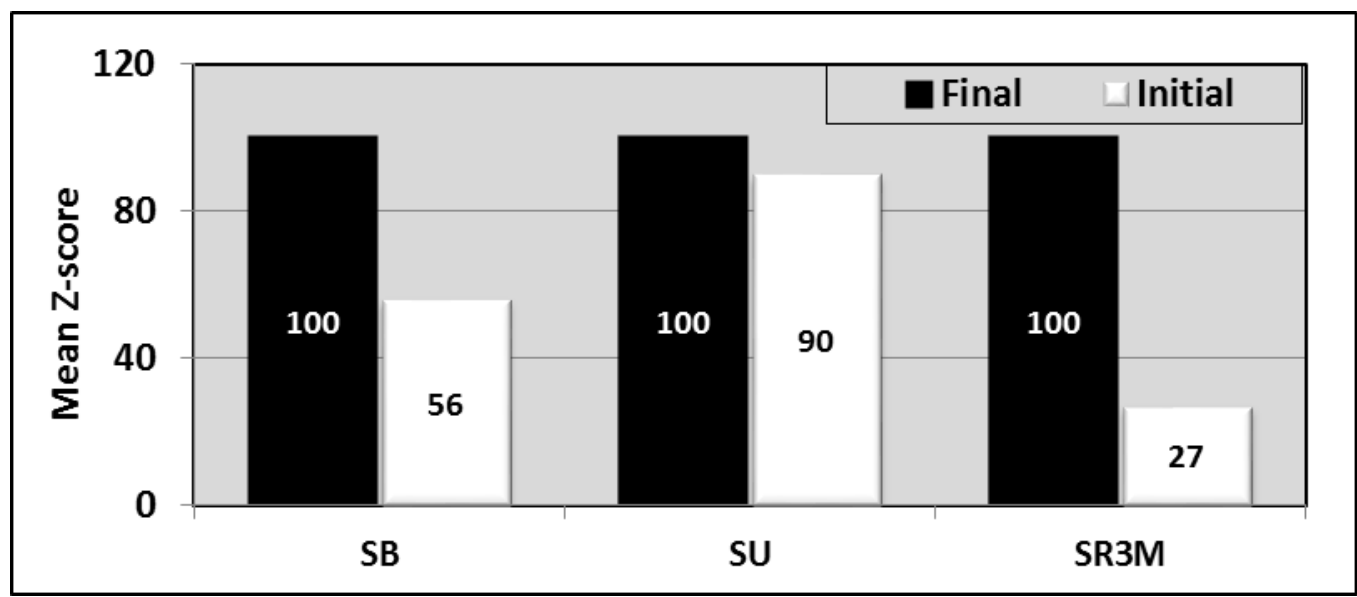

The sand bag (150 g) throw for distance with dominant hand tested the Explosive strength and Coordination. There was a statistically significant improvement in the results from an average of $485 \mathrm{~cm}$ to $526 \mathrm{~cm}$. The applied sports program included a large number of exercises for the upper body and arms and in this way influenced the development of strength of the upper extremities and shoulders.

In the "sit-ups" test, which measures the repetitive strength of the trunk, great progress was noticed. The results improved from 7.7 repeats in the initial measuring to 9.4 repeats in the final one. A significant improvement in this test is expected because repetitive strength is influenced by regular exercise and by doing specific exercises.

In the test of shuttle run in 3 min tested the cardio respiratory endurance. the children improved their result from $298.35 \mathrm{~m}$ in the initial measuring to $321.51 \mathrm{~m}$ in the final one. It means that the children improved their result by $25 \mathrm{~m}$ and made a statistically significant improvement over the three-month period.

The results of the initial measuring of both groups for the purpose of a precise comparison are shown in (Table 4). It can be seen from the results of the initial measuring, that there is no statistically significant difference of variables among the group,

Table (4)

Results of the initial measuring between the control (M1) and experimental group (M2)

\begin{tabular}{|c|c|c|c|c|c|c|c|}
\hline \multirow{3}{*}{ Variables } & \multicolumn{4}{|c|}{ Groups } & \multirow{3}{*}{$\begin{array}{c}\text { Mean } \\
\text { Diff. }\end{array}$} & \multirow{3}{*}{$\mathrm{t}$} & \multirow{3}{*}{$\mathrm{p}$} \\
\hline & \multicolumn{2}{|c|}{ Cont. } & \multicolumn{2}{|c|}{ Exp. } & & & \\
\hline & M1 & SD1 & M2 & SD2 & & & \\
\hline $\mathrm{S} \& \mathrm{R}(\mathrm{cm})$ & 20.08 & 3.03 & 20.17 & 3.31 & .092 & .128 & .898 \\
\hline $\mathrm{SLJ}(\mathrm{cm})$ & 90.16 & 2.87 & 90.20 & 3.28 & .037 & .053 & .957 \\
\hline SR4x10 (s) & 15.20 & 1.84 & 15.40 & 1.86 & .021 & .491 & .624 \\
\hline $\mathrm{SB}(\mathrm{cm})$ & 484.11 & 5.69 & 484.60 & 6.24 & .480 & .356 & .723 \\
\hline SU (n/30s) & 7.40 & 1.82 & 7.66 & 1.87 & .264 & .635 & .527 \\
\hline SR3M (m) & 297.19 & 2.90 & 298.35 & 3.12 & 1.16 & 1.70 & .093 \\
\hline
\end{tabular}

The results of the final measuring of both are shown in Table 5, Figure 3-A and Figure 3groups for the purpose of a precise comparison B. 
Table (5)

Results of the final measuring between the control (M1) and experimental group (M2)

\begin{tabular}{|c|c|c|c|c|c|c|c|}
\hline \multirow{3}{*}{ Variables } & \multicolumn{4}{|c|}{ Groups } & \multirow{3}{*}{$\begin{array}{c}\text { Mean } \\
\text { Diff. }\end{array}$} & \multirow{3}{*}{$\mathrm{t}$} & \multirow{3}{*}{$\mathrm{p}$} \\
\hline & \multicolumn{2}{|c|}{ Cont. } & \multicolumn{2}{|c|}{ Exp. } & & & \\
\hline & M1 & SD1 & M2 & SD2 & & & \\
\hline $\mathrm{S} \& \mathrm{R}(\mathrm{cm})$ & 21.13 & 3.01 & 22.24 & 3.27 & 1.11 & 1.57 & .120 \\
\hline SLJ (cm) & 90.53 & 2.56 & 101.07 & 3.43 & 10.55 & 15.40 & .000 \\
\hline SR4x10 (s) & 14.66 & 1.25 & 14.21 & 1.21 & 0.45 & 1.62 & .109 \\
\hline $\mathrm{SB}(\mathrm{cm})$ & 485.39 & 6.48 & 526.27 & 9.52 & 40.87 & 22.13 & .000 \\
\hline SU (n/30s) & 7.71 & 1.58 & 9.44 & 1.80 & 1.73 & 4.52 & .000 \\
\hline SR3M (m) & 301.63 & 2.62 & 321.51 & 3.18 & 19.88 & 30.19 & .000 \\
\hline
\end{tabular}

A comparison of the results of the final experimental group achieved significantly better measuring (Table 5) makes it obvious that the results for all of the variables.

Figure (3-A)

Results of the final measuring (Z-Score) of the control and experimental group

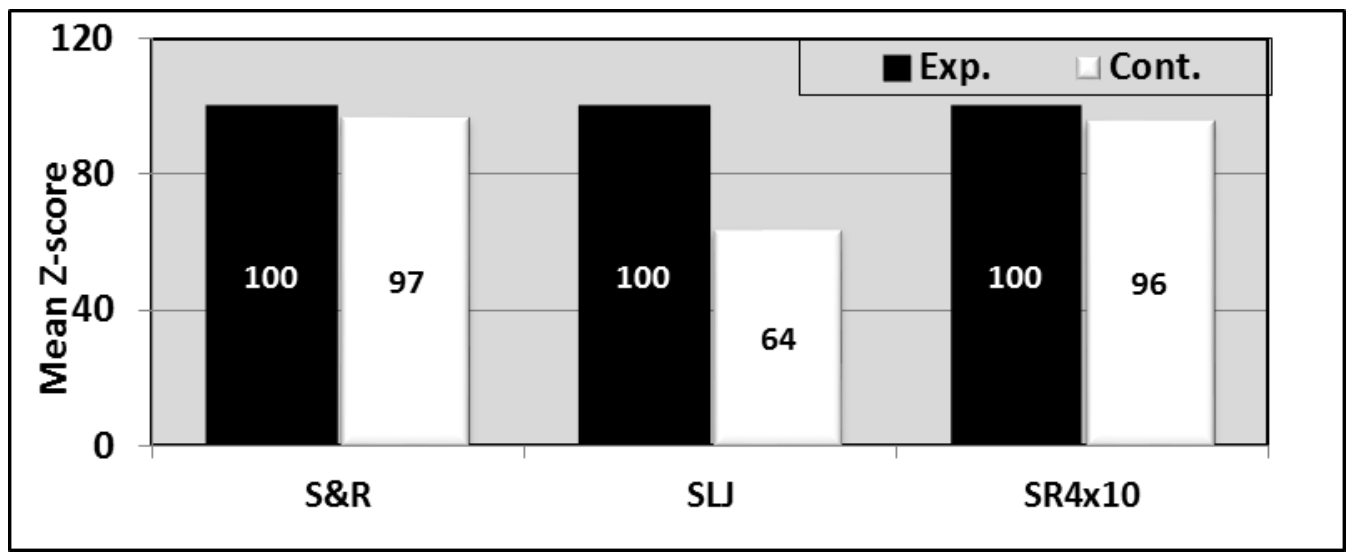

There was no significant difference in standing long jump score between experimental and control groups before sports program (Table 4). The mean standing long jump score for the experimental group pre training was $90.20 \mathrm{~cm}$, whereas for control subjects, it was $90.16 \mathrm{~cm}$. After 12 weeks of sport training, the experimental group scored significantly higher on the standing long jump compared with control subjects with a similar baseline (Table 6) (Fig 3-A). After training, the experimental group averaged $101.07 \mathrm{~cm}$, whereas control subjects averaged $90.53 \mathrm{~cm}$. There was no a statistically significant improvement in the results of the sit-and reach and shuttle run $4 \times 10$ tests.

Figure (3-B)

Results of the final measuring (Z-Score) of the control and experimental group

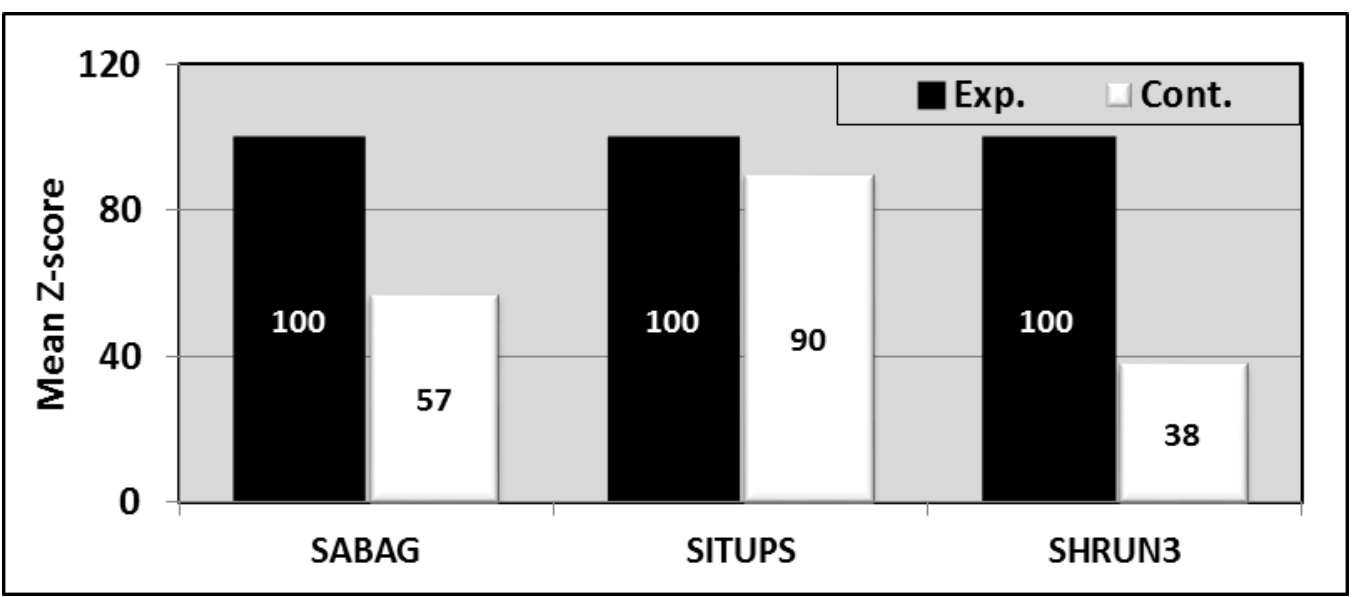

Before sport program, there were no significant $3 \mathrm{~min}$ tests between experimental and control differences in sand bag, sit-ups and shuttle run groups (Table 4). The experimental group mean 
before training were $484.6 \mathrm{~cm}, 7.66 \mathrm{n} / 30 \mathrm{~s}$ and $298.35 \mathrm{~m}$., whereas for control subjects, it were $484.11 \mathrm{~cm}, 7.4 \mathrm{n} / 30 \mathrm{~s}$ and 297.19 meter. When measured after three months of sport training, there were significant differences in the experimental group's mean (Fig 3-B) where their values increased to an average of $41.7 \mathrm{~cm}$, 1.8 trials and 24.6 meter, whereas control subjects scored $1.3 \mathrm{~cm}, 0.3$ trials and 3.4 meter.

\section{Future implications}

More studies such as this one are needed to better understand changes in motor abilities over time. The subjects for this study were preschool children, further studies will comprise more different ages.

\section{Conclusion}

The obtained results indicate that the experimental program achieved the set objectives and tasks, aimed primarily at the development and improvement of the motor abilities of preschool children at the age of five.

This paper proves that changes in the motor abilities of preschool children at the age of five, who attended a special sports program, did take place. In comparison with the other sports program (Council on Physical Education for Children, 1992, Mitchell, Davis \& Lopez 2002), it has to be emphasized that every planned and well aimed exercise program has a positive impact on the development of primary motor abilities of children at a very young age. For this reason, it can be recommended as one of the components of the daily creative planning of leisure time of children at a very young age, as part of an organized educational and learning program.

\section{Acknowledgements}

The author would like to acknowledge the support of the staff and children of Good shepherd School. There has been no external financial support for this study.

\section{References}

1. Avery, M. (1994). Preschool physical education: A practical approach. Journal of Physical Education, Recreation and Dance, 65(6), 37-39.
2. Biddle, S. J. H., Gorely, T., \& Stensel, D. (2004). Health-enhancing physical activity and sedentary behaviour in children \& adolescents. Journal of Sport Science, 22, 679-701.

3. Brian W. Timmons, Patti-Jean Naylor, and Karin A. Pfeiffer, (2007). Physical activity for preschool children how much and how? Canadian Public Health Association Appl. Physiol. Nutr. Metab. 32: S122-S134.

4. Brown, W. H., Pfeiffer, K. A., McIver, K. L., Dowda, M., Almeida, M., Joao C.A., \& Pate, R. R. (2006). Assessing preschool children's physical activity: the observational system for recording physical activity in children-preschool version. (Measurement and Evaluation). Research quarterly for exercise and sport, 77(2), 167-176.

5. Bruininks, R. H., \& Bruininks, B. D. (2005). Bruininks-Oseretsky Test of Motor Proficiency (2nd ed.). Windsor: NFER-Nelson.

6. Butterfield, S.A., Lehnhard, R.A. \& Coladarci, T. (2002). Age, sex and body mass index in performance of selected locomotor and fitness tasks by children in grades k-8. Perceptual and Motor Skills, 94, 80-86

7. Chambers, M., \& Sugden, D. (2006). Early years movement skills: Description, diagnosis and intervention. West Sussex, England: Whurr Publishers.

8. Community Information Service (1996). Fundamental Motor Skills A Manual for Classroom Teachers Department of Education, GPO Box 4367, Melbourne Vic 3001, Australia.

9. Council on Physical Education for Children (COPEC). (1992). Developmentally appropriate physical education practices for children: A position statement of the Council on Physical Education for Children. Reston, VA: National Association for Sport and Physical Education.

10. Dietz, J. C., Kartin, D., \& Kopp, K. (2007). Review of the Bruininks-Oseretsky Test of Motor Proficiency, second edition (BOT-2). Physical \& Occupational Therapy in Pediatrics, 27, 87-102.

11. Demiral, S. (2011). The Study of the Effects of Educational Judo Practices on Motor Abilities of 7-12 Years Aged Judo Performing Children. Canadian Center of Science and Education, Asian Social Science, 7, 212-219. 
12. Dorfberger S, Adi-Japhab E, Karnia A, 2009. Sex differences in motor performance and motor learning in children and adolescents: An increasing male advantage in motor learning and consolidation phase gains, Behavioural Brain Research 198, 165-171

13. Dowda, M., Pate, RR., Trost, SG., Almeida, MJ., \& Sirard, JR. (2004). Influences of preschool policies and practices on children's physical activity. Journal of Community Health, 29(3), 183-196.

14. Finn, K, Johannson, N, \& Specker, B. (2002). Factors associated with physical activity in preschool chil- dren. Journal Pediatric, 140, 81-85.

15. Fischer, A., Reilly, J., Kelly, L., Montgomery, C., Williamson, A., \& Patton, J. (2005). Fundamental movement skills and habitual physical activity in young children. Medicine and Science in Sports and Exercise, 37, 36-46.

16. Hands B, 2008. Changes in motor skill and fitness measures among children with high and low motor competence: A five-year longitudinal study, Journal of Science and Medicine in Sport 11, 155-162

17. Hands B, Larkin D, Parker H, Straker L, Perry M, 2009. The Relationship between Physical Activity, Motor Competence and Health related Fitness in 14-year-old Adolescents, Scandinavian Journal of Medicine and Science in Sports, Vol. 19 (5), p. 655-663.

18. Hands, B., \& Martin, M. (2003). Fundamental movement skills: Children's perspectives. Australian Journal of Early Childhood, 28, 47-52.

19. Hay, J., Hawes, R., \& Fraught, B. (2004). Evaluation of a screening instrument for Developmental Coordination Disorder. Journal of Adolescent Health, 34, 308-313.

20. Henderson, S. E., Sugden, D. A., \& Barnett, A. L. (2007). Movement assessment battery for children (2nd ed.). London: Harcourt Assessment.

21. Hraski, Ž., Živiü, K. (1996). The basic of realization and curriculum contents of kinesiology activity in project "Kindergartens"). Unpublished project of MSES, Zagreb: International Sport Programs, Kindergarten "Vjeverica".
22. Hu1-Tzu, W. (2003). The Effects of a Creative Movement Program on Motor Creativity and Gross Motor Skills of Preschool Children, Doctor of Education, The University of South Dakota, USA .

23. Ikeda T, Aoyagi O, (2008). Meta-analytic Study of Gender Differences in Motor Performance and Their Annual Changes among Japanese Preschool-aged Children, School Health 4, 24-39

24. Graf C, Koch B, Kretschmann-Kandel E et al. (2004). Correlation between BMI, leisure habits and motor abilities in childhood (CHILTproject). Int J Obes Relat Metab Disord, 28, 2226.

25. Gallahue, D.L. and Donnelly, F.C. (2003) Development physical education for all children, 4th.Human Kinetics: Champaign, pp. 24-49.

26. Graham, G., Holt/Hale, S. A. \& Parker, M. (1998). Children moving: A reflective approach to teaching physical education. Mountain View, CA: Mayfield.

27. Jackson, D.M., John, J. R., Kelly, L. A., Montgomery, C., Grant, S., \& Paton J. Y. (2003). Objectively Measured Physical Activity in a Representative Sample of 3- to 4-Year-Old Children. Obesity Research 11, 420-425.

28. Kostiü, R., Miletiü, Ĉ., Jociü, D., Uzunoviü, S. (2003). The influence of dance structures on the motor abilities of preschool children. Facta Universitatis, Series Physical Education and Sport, 1(9), 83-90.

29. Mandich, A. D., Polatajko, H. J., \& Rodger, S. (2003). Rites of passage: Understanding participation of children with Developmental Coordination Disorder. Human Movement Science, 22, 583-595.

30. Melody, O., Schofield, G.M., \& Kolt, G.S. (2007). Physical Activity in Preschoolers: Understanding Prevalence and Measurement Issues. Sports Medicine, 37(12), 1045-1070.

31. Mitchell, D., Davis, B., \& Lopez, R. (2002). Teaching Fundamental Gymnastics skills. Champaign, IL: Human Kinetics.

32. National Association for Sport and Physical Education (NASPE). (2002). Active Start - A Statement of Physical Activity Guidelines for Children Birth to Five Years. 
33. Oja L. \& Juerimaee T. (1997). Assessment of Motor Ability of 4- and 5-Year-Old Children, American journal of human biology 9:659-664

34. Pate R.R., Pfeiffer K.A., Trost S.G., Ziegler P., \& Dowda M. (2004). Physical activity among children attending preschools. Pediatrics, 114(5), 1258-63.

35. Piek, J. P., et al (2012). Does the Animal Fun program improve motor performance in children aged 4-6 years? Human Movement Science.

36. Rigoli, D., Piek, J. P., \& Kane, R. (2012). Motor skills and psychosocial correlates in a normal adolescent sample. Pediatrics, 129, e892-e900.

37. Salman, Z. (1993). Examining the effect of physical activities and playing in mental development of preschool children, M.A. Thesis, Tarbiat Modarres University.

38. Sanders, S. W. (1992). Designing preschool movement programs. Champaign, IL: Human Kinetics.

39. Sanders, S. (1993). Developing appropriate movement practices for 3- to 5- year olds. Teaching Elementary Physical Education, 4(5), $1,7,11,16$.

40. Sheikh, M. (2003). Effect of physical activity on fundamental skills in secondary school boys, journal of movement, physical education faculty, University of Tehran.

41. Sheikh M., Safania A. M., Javad Afshari J. (2011). Effect of selected motor skills on motor development of both genders aged 5 and 6 years old. Procedia Social and Behavioral Sciences 15: $1723-1725$

42. Shenouda, N., Gabel, L., \& Timmons, B.W., (2011). Preschooler physical activity and motor skill development, child health \& exercise medicine program, 3 .
43. Smits-Engelsman, B. C. M., Niemeijer, A. S., \& van Waelvelde, H. (2011). Is the Movement Assessment Battery for Children2nd edition a reliable instrument to measure motor performance in 3 year old children? Research in Developmental Disabilities, 32, 1370-1377.

44. South Eastern Sydney Illawarra Area Health Service (1997). Kindarobics - Pre-School Gross Motor Skills Project. Illawarra Child Development Centre 42a Porter Street, North Wollongong.

45. Strauss, R.S., Rodzilsky, D., Burack, G, \& Colin, M. (2001). Psychosocial correlates of physical activity in healthy children. Archive Pediatric \& Adolescent Medicine, 155, 897-902.

46. Technical Assistance \& Training System (TATS) (2010). Developmentally Appropriate Practice - Motor Skills. Florida

47. Thelen, E. (1995). Motor development: A new synthesis. American Psychologist, 50, 7995.

48. Trajkovski - Višiü, B. (2004). Influence of the sport program for the changing motor and mor-phological characteristics in the age of four. Unpublished Master's thesis, Zagreb: Faculty of Kinesiology University of Zagreb.

49. Van Waelvelde, H., de Weerdt, W., de Cock, P., \& Smits-Engelsman, B. C. M. (2003). Ball catching. Can it be measured? Physiotherapy Theory and Practice, 19, 259-267.

50. Venetsanou, F., \& Kambas, A. (2010). Environmental factors affecting preschoolers motor development. Early Childhood Educational Journal, 37, 319-327.

51. Werner, P. (1997). The national standards and common sense: Using them together to determine what is developmentally appropriate. Teaching Elementary Physical Education, 8(2), 6-8. 